\title{
Examination of Laser Microwelded Joints of Additively Manufactured Individual Implants
}

\author{
János KÓNYA, ${ }^{1}$ Klaudia KULCSÁR ${ }^{2}$ \\ ${ }^{1}$ Dent-Art-Technik Kft. Győr, Hungary, labor@dentarttechnik.hu \\ ${ }^{2}$ Dent-Art-Technik Kft. Györ, Hungary, kulcsar.klaudia@dentarttechnik.hu
}

\begin{abstract}
Digital product processing and the utilization of novel, tissue-friendly materials allow the use of fixed dentures for patients. Its basis is a titanium plate fixed to the cortical bone surface at given screw positions. A digital dental cast is created from the existing bone surface, and modelling and necessary statistical analyses are carried out in a virtual environment. Safety of the welded joint is evaluated with mechanical methods. When designing the fixing points, an idealized denture is used that was previously designed for the patient. The number and position of pillar elements used for screw fixation of the denture are determined by the complex geometry of the denture itself, and the location, direction, and articulating position of existing teeth. The additively manufactured implant and the machined pillar sleeves are joined with laser-welding at given nesting positions. Homogeneity of the metallic material structure at the welded joint zone of the product is examined with micro-CT. Due to this implementation method, surgical time decreases together with complication rates and post-operative problems.
\end{abstract}

Keywords: additive manufacturing, implant, laser micro welding, titanium, 3D printing.

\section{Introduction}

Titanium and its alloys are among the best metallic materials of choice in industrial and medical applications. Ti-6Al-4V alloy is mainly used in aerospace and for surgical implant material as well due to its high tensile and fatigue strength and good corrosion resistance [1]. Titanium - commercially pure titanium or titanium alloy - welding can be necessary in aerospace industry, but also in the manufacturing of medical instruments. Titanium and its alloys have several advantages in surgical implant and prosthesis manufacturing because of their outstanding corrosion resistance, mechanical properties, and biocompatibility [2]. Laser welding is present in the manufacturing process of diverse medical products, such as pacemakers, defibrillators, catheters, and orthopaedic implants [3]. Biocompatible metals and alloys e.g. titanium, nitinol, cobalt-based alloys, stainless steel, platina, and niobium are used for implantable devices. Titanium is a unique material that requires special attention in every processing step, especially in welding [4]. Titanium has a complicated welding technology as at temperatures higher than $550{ }^{\circ} \mathrm{C}$, and especially in liquid phase, it is highly reactive with atmospheric gases such as oxygen and nitrogen. Inadequate preparation or cleaning of jointing and filling materials, insufficient protection of weld joint zone or inert gas contamination before or during welding can cause material impurities [5-7].

Several joining technologies are used for titanium materials, for example tungsten inert gas welding, laser welding, and brazing [2]. Three different techniques for jointing material layup on metallic components are investigated in today's practice: direct laser welding, electron beam deposition [8-10], and shaped metal deposition (SMD) [11]. Argon atmosphere provides a cost-effective solution compared to processes that require a high vacuum chamber [15]. Titanium welding is mostly carried out with a high-energy beam in inert atmosphere. Electron beam welding, despite its high costs, is fully capable of fusing 
titanium particles together. The vacuum chamber protects high-temperature material during the welding process and impurities will not be present $[16,17]$. The widely-used welding process for titanium alloys is gas tungsten arc welding due to its simple applicability and cost-effectiveness. Magnetic arc oscillation and electric current impulse welding are more popular as these technologies are possibly applicable in actual industrial situations with minor modifications of existing welding machines [18].

Several studies investigated the effect of air contamination on the microstructure and mechanical properties of welded joints in pure titanium and titanium alloys [19]. Two welding technologies were compared in additively manufactured Ti-6Al-4V alloy: one possible solution was Nd:YAG laser welding, the other was tungsten inert gas welding [20]. Several methods were successfully implemented to obtain a fine-grained microstructure at the welded joint zones, such as surface nucleation induced by choked gas flow. Experiments with grade 2 titanium alloy concluded that welded zone pigmentation is correlated with the absence of inert gas, oxygen and nitrogen content in welded zones, and mechanical properties of the joint [19]. However, this correlation is also affected by other variables apart the surficial colour of the welded joint and material impurities. It was detected that the surface colour of the welded zone only indicated surficial impurities [19]. The effect of oxygen contamination in the argon atmosphere on welded material microstructure and material properties was investigated during laser welding of thin titanium plates. Welded joint examination was carried out mostly with optical and scanning electron microscopes. Mechanical tests revealed a relationship between the colour of the welded joint surface and the structure and mechanical properties (strength, ductility, hardness) of the welded joint [19].

\section{Precision cast subperiosteal implant}

The re-thought implant structure was created with a conventional casting process, which met considerable practical difficulties. Necessary manual post-processing steps become more difficult due to problems with metal structure homogeneity, wear and erosion of the ceramic embedding cast, and embedding of ceramic wear debris into the implant structure. The cast contained only one structural element where the perforated membrane for the contact surface and the fixing pillars were cast together as one piece (Figure 1.). Design of screw locations was carried out after parallel positioning.

The metal structure was subjected to non-destructive material testing with micro-CT to analyse material homogeneity after hole-drilling and threading (Figure 2.). During software evaluation of results, material defects were found in more than $80 \%$ of casts. The purpose of our first corrective measure was to open up and fill internal voids using a laser welding machine. Following this intervention, mechanical strength and machinability of this filled-up material structure differed from the original cast material, which further aggravated the creation of fixing points.

\section{Design and evaluation of dual-phase pillars}

Using the previous results and experiences a complex new solution was found. It meant the laser welding of the cast base structure and the machined axis-symmetric and parallel pillar elements. The final fixing points had already been created on these pillar elements. It provided a good technical solution as it allowed the necessary mechanical strength and structural stability. The precise machinability of the welded pillar element connecting to the base structure made it possible to create high-precision surficial fitting for further implant connecting elements.

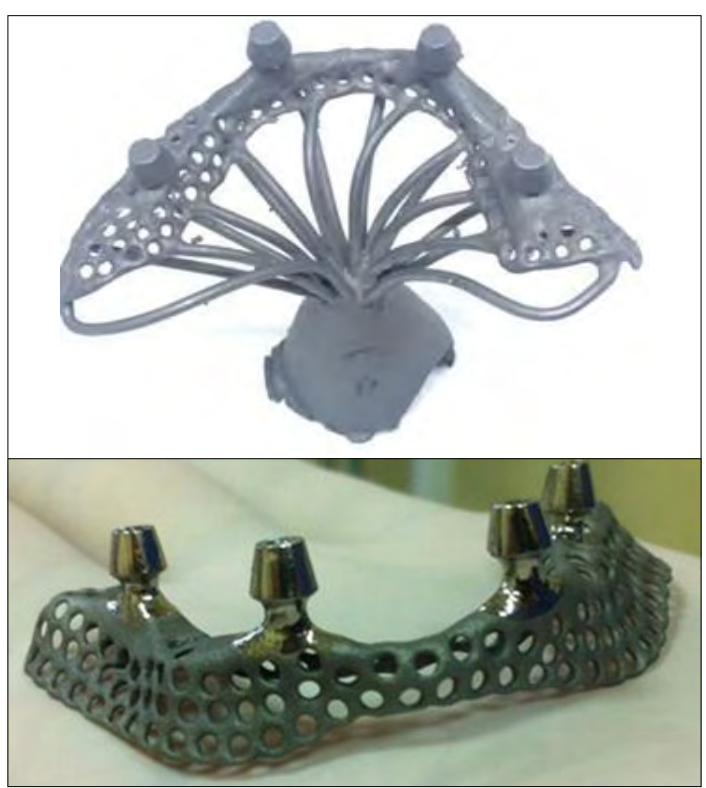

Figure 1. Raw cast of one-piece titanium metal structure, and the device ready to be implanted 
Connecting elements for this dual-phase implant were necessary so that the surgical wound could be closed during the implantation procedure and healing time was reduced. Hereby, threaded sleeves of fixing pillars can be closed with so called healing screws.

Other advantages of threaded sleeves are detachability, maintainability, and diversity of pillar geometries that are applicable in different environments. It embodies the possibility of both axis correction and solutions for special anatomical positions and different gingival thicknesses.

Our implants that had been manufactured previously in this way did not possess a thorough background in material testing and structure
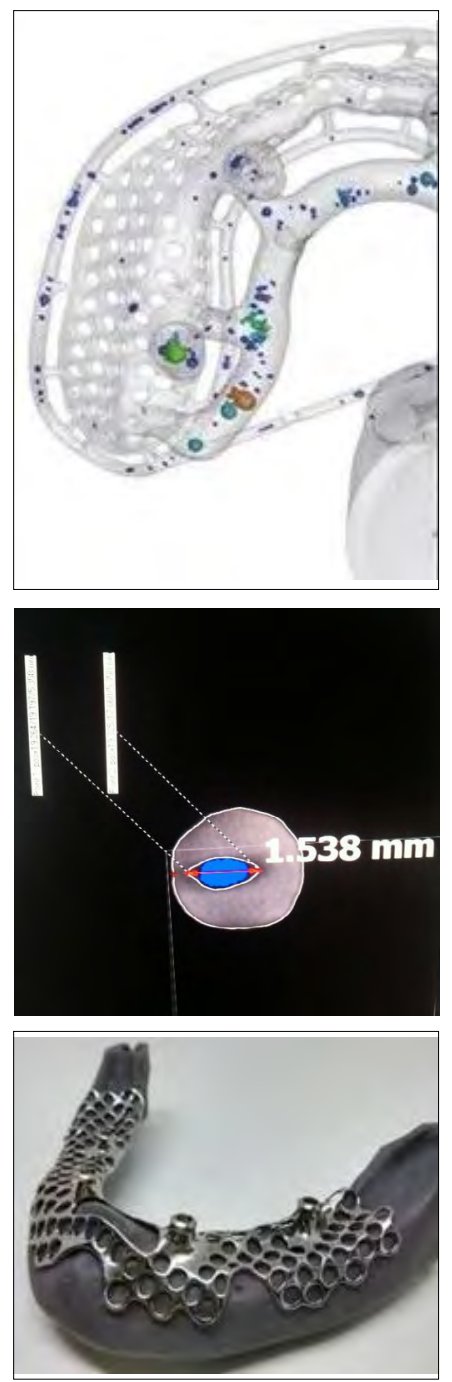

Figure 2. Revealed material continuity defects and void fractions in micro-CT images analysis. It was provided by virtual design, a new level of information retrieved from (Cone Beam Computer Tomography) CBCT images, and special software. Hereby, the subperiosteal implant was completely re-thought. It was now manufactured with 3D subtractive technology after virtual product design. Both the frame structure, the fixing pillars, and their proper connection were designed and implemented by considering the possibilities of modern computer science together with our previous experiences (Figure 3.).

\section{Finite element analysis of the frame structure}

Finite element analysis utilizes the mathematical model of the physical structure. It contains structural parts, material models, boundary conditions, and all other properties that model physical reality (Figure 4.).
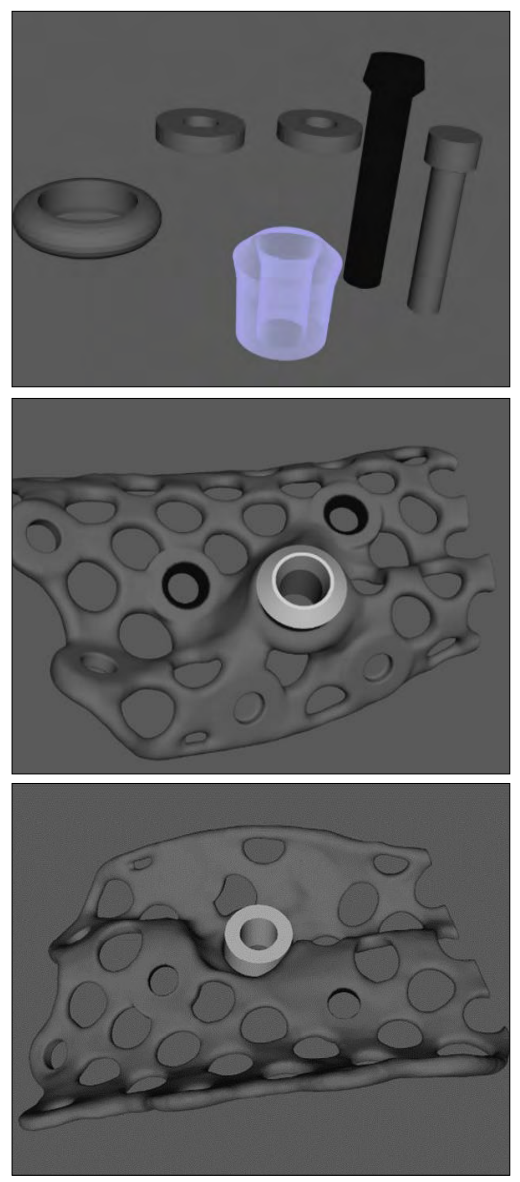

Figure 3. Virtual joining of designed pillar elements with the frame structure 
Stress distribution of the membrane was examined with finite element analysis in locations where the threaded sleeve, which holds the implant superstructure, is attached with laser micro welding. Figure 5. shows the direction of mechanical loads and stress distribution. In this case, an axial occlusal force of $150 \mathrm{~N}$ and its horizontal components were determined for implant loading. Hereby, an average of $15 \mathrm{~mm}$ interocclusal distance was calculated for cases of bone deficiency.

Finite element analysis provided a great support for determining dimensions of the frame structure. Frame extension, peripheries, minimum material thickness, perforation diameter, consistence, and position were all idealised for a given load.

\section{Mechanical testing of welded titani- um alloy specimens}

The material of structural parts such as frame and threaded sleeve were both titanium alloys. The frame structure, however, was built up with additive manufacturing process from Grade 23 titanium material, while the $\mathrm{CNC}$ machined threaded sleeves were made from Grade 5 titanium rods. We had previous practical experiences regarding cast Grade 1 and Grade 5 titanium welding with Grade 1 filler material. Their quality and material homogeneity had been evaluated with micro-CT analysis. These experiences made it necessary for us to test the new welded structure as well.

Additively manufactured Grade 23 titanium test specimens were subjected to structural material testing. Comparative tensile testing was also conducted during which test specimens were cut apart and then joined back together with laser micro welding to retain their original geometry.

Firstly, simple test specimens were used (Figure 6.). We observed that the extent of tensile elongation at break can affect the strength of the welded structure itself (Figure 7.).

$\mathrm{Az}$ eredeti próbatest módosítására azért volt szükség, hogy a szakadási nyúlás mértékét csökkentsük.

The modification of the original test specimen was necessary to minimize tensile elongation at break.

The modified geometry was determined based on this approach (Figures 8. and 9. ).

Cut and welded test specimens were created, and the comparative tensile test was repeated (Figures 10., 11. and 12. ábra).

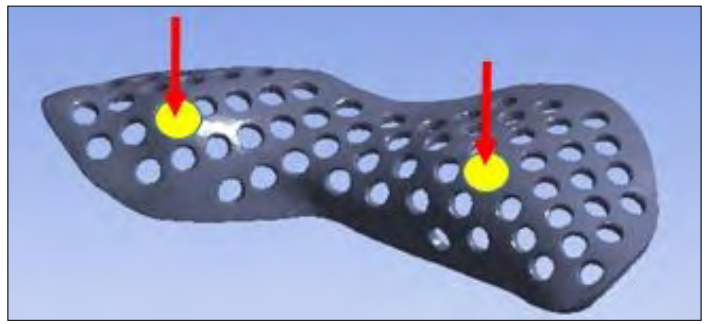

Figure 4. Pillar positioning on the solid model

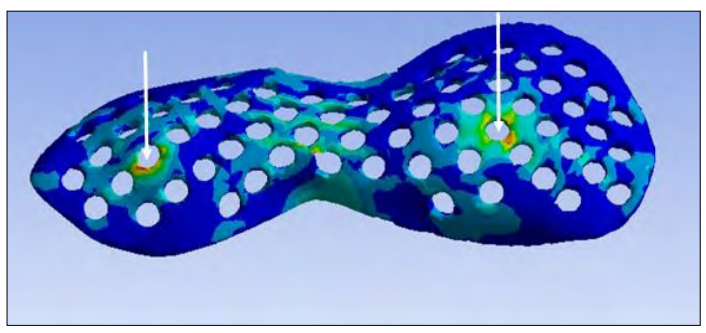

Figure 5. Stress distribution nearby the placed pillar elements

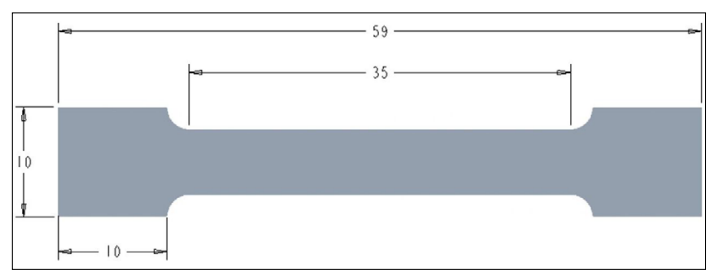

Figure 6. Original test specimen

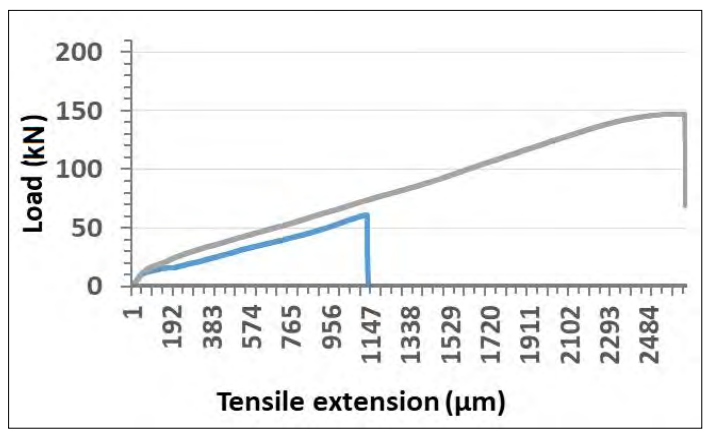

Figure 7. Force-displacement curve of original test specimens. Grey colour indicates the original, blue indicates the welded test specimens

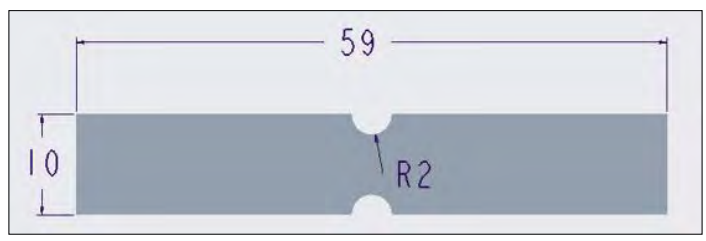

Figure 8. Modified test specimen 


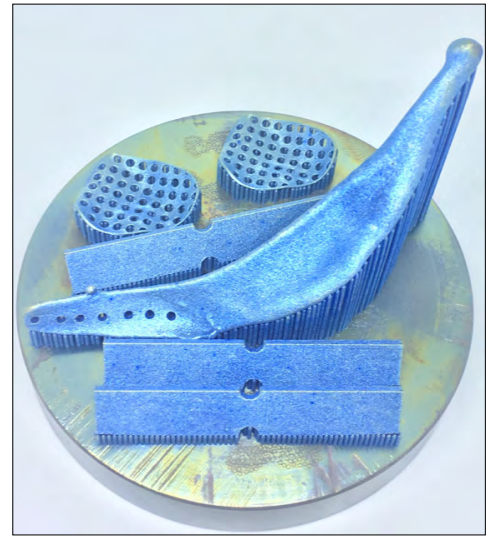

Figure 9. Additive manufacturing of test specimens

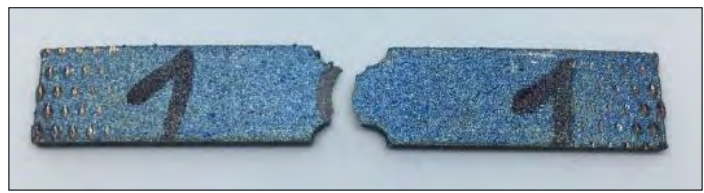

Figure 10. Split modified test specimen

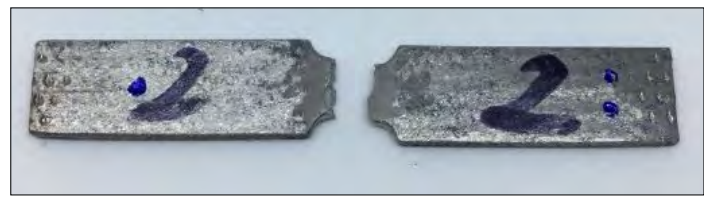

Figure 11. Split welded and modified test specimen

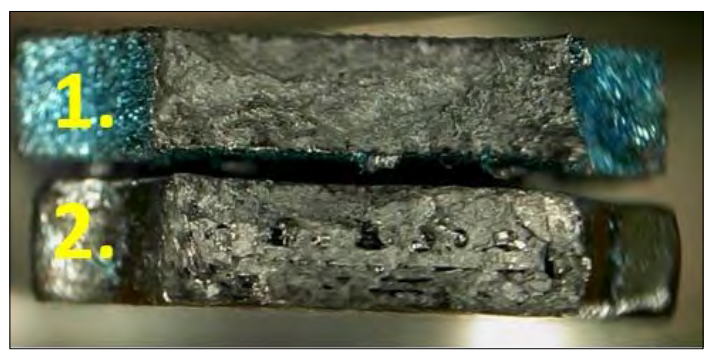

Figure 12. Fracture surfaces of test specimens: no. 1 is modified and no.2 modified and welded test specimen

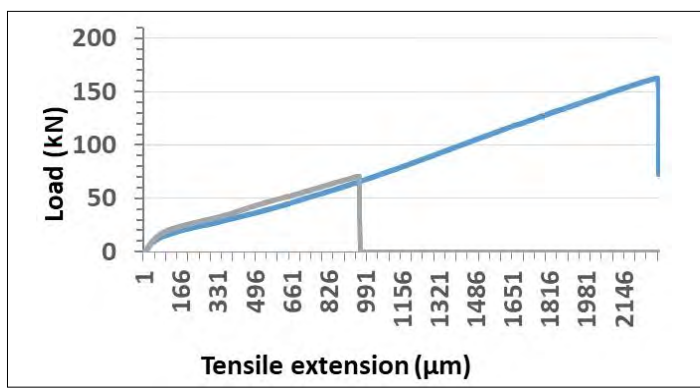

Figure 13. Force-displacement curve of modified test specimens. Colour blue indicates the original, grey indicates welded test specimen
Based on results of tensile testing and comparative numerical analysis of stress distributions in frame structures, we conclude that the mechanical strength of the welded joint fulfils the expected physical requirements. According to our calculations, the welded structure can withstand forces twenty times higher than the average axial articulation force (considering $140 \mathrm{~N}$ average acting force) (Figure 13.).

\section{Base plate created with additive man- ufacturing}

Precision casting could be substituted due to development in manufacturing technology and available machinery. The idea presented itself to create the additively manufactured - Selective Laser Melting (SLM) - base plate together with fixing points in one structure. Machining became complicated because of the relative material brittleness resulting from the heat treatment, which was carried out according to the manufacturer's recommendations, of the printed metal structure (Figure 14.). The use of conventional screw taps

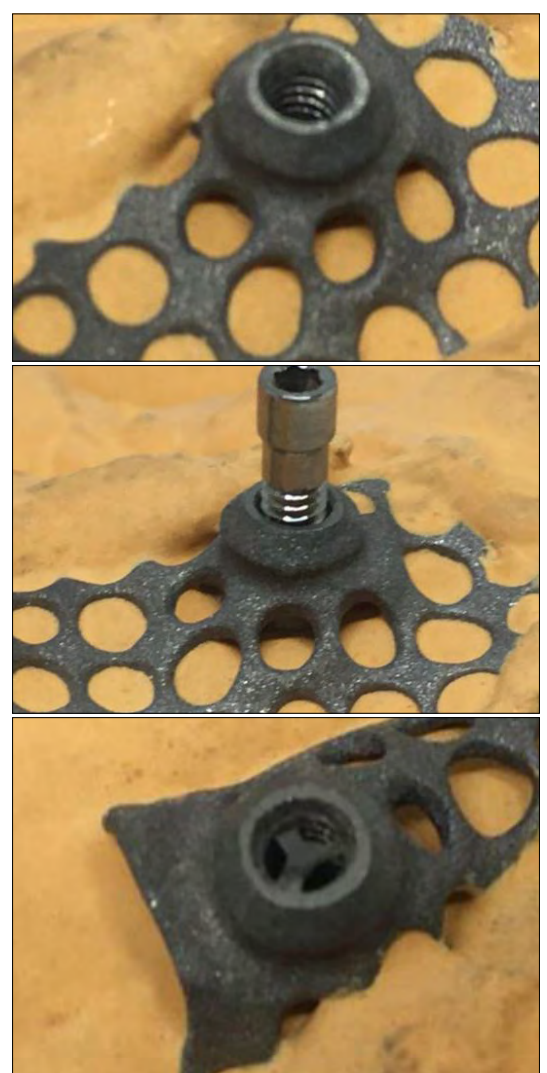

Figure 14. Examples of unsuccessful machining outcomes of one-piece-printed metal structures 
was not possible. Precision post-machining of further implant fitting surfaces was also problematic as accurate fixing and positioning of the workpiece was not accomplishable.

Clear results of our investigation and experiences showed that laser welding is the most precise and cost-effective method to join the 3D-printed base plate with the threaded sleeves, which provide dual-phase fixing. It necessitated the use of virtual elements during product design. They defined the exact location of the sleeves and joint geometry parameters such as groove angles material thicknesses (Figure 15. and Table 1. ).

The 3D-printed metal part went through stress relieving heat treatment for 20 minutes on $600{ }^{\circ} \mathrm{C}$ (atmospheric pressure, without protective gas). It was followed by corundum particle blasting on 3-4 bar with a particle size of $50 \mu \mathrm{m}$. After manual surface processing, the two ele-
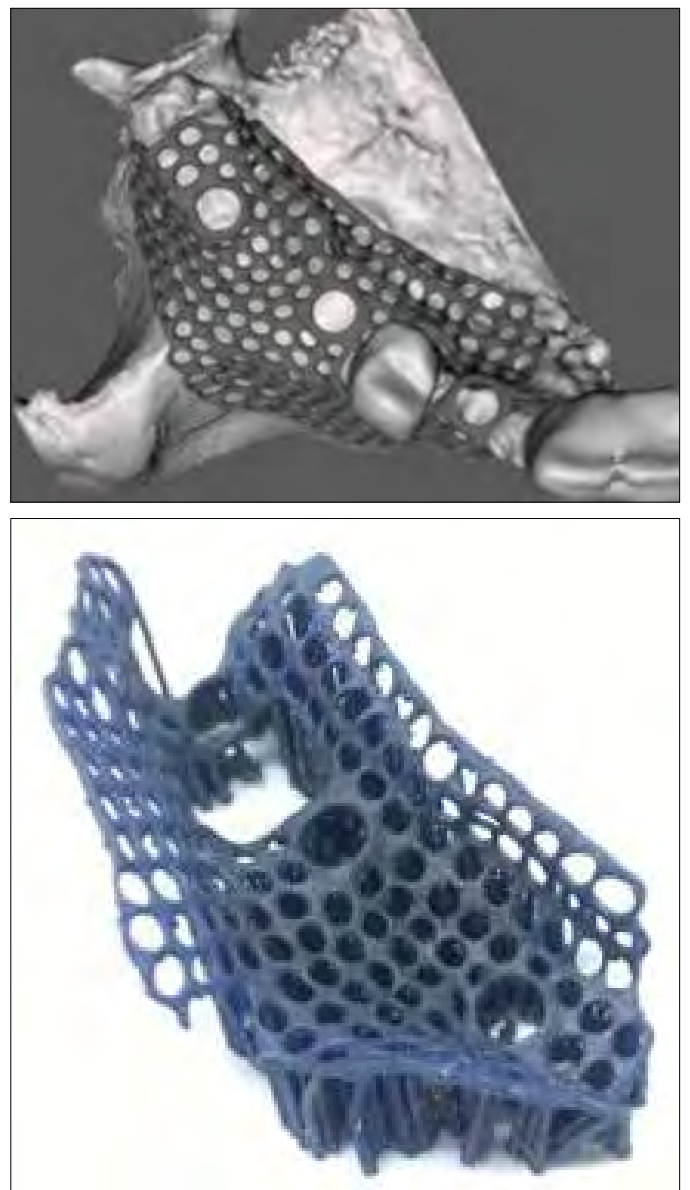

Figure 15. Base plate created with additive manufacturing (powder bed fusion), and the printed solid part with support structures
Table 1. Technical parameters of the additive laser manufacturing unit

\begin{tabular}{|l|l|}
\hline \multicolumn{1}{|c|}{ Technical parameters } & \multicolumn{1}{c|}{ SISMA mysint100 } \\
\hline Effective cylinder volume & dia. $100 \times 100 \mathrm{~mm}$ \\
\hline Max output power & $200 \mathrm{~W}$ \\
\hline Laser spot diametre & $50 \mu \mathrm{m}$ \\
\hline Tipical layer thickness & $20-40 \mu \mathrm{m}$ \\
\hline Power supply & $220-240 \mathrm{~V} / 50-60 \mathrm{~Hz}$ \\
\hline Max. power absorbed & $1,53 \mathrm{~kW}$ \\
\hline Inert protection gas & nitrogen, argon \\
\hline Inert gas supply & $6 \mathrm{~mm} / 2,5-5$ bar $35 \mathrm{~L} / \mathrm{min}$ \\
\hline Inert gas consumption & $<0,3 \mathrm{~L} / \mathrm{min}$ on $0,5 \% \mathrm{O}_{2}$ \\
\hline $\mathrm{O}_{2}$ concentration & $0,3 \%$ \\
\hline Equipment dimensions & $1390 \times 777 \times 1600 \mathrm{~mm}$ \\
\hline Equipment weight & $650 \mathrm{~kg}$ \\
\hline
\end{tabular}
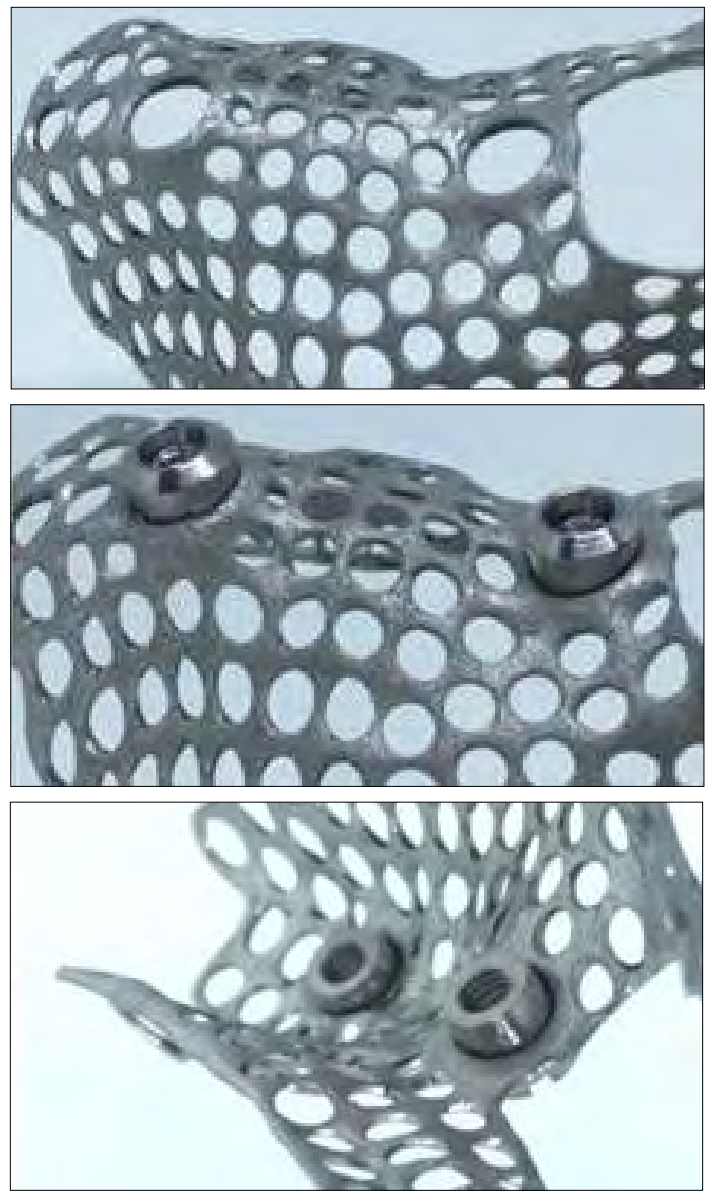

Figure 16. Structural part assembly for welding: joining sleeve components 
ments were positioned together (Figure 16.) for welding according to the existing virtual design. Simultaneously, complex parallelism check of the fixing elements is necessary. Assembly of structural elements was done on the SLA 3D-printed photopolymer bone surface, which had been generated from DICOM file of the CBCT image.

\section{Laser beam welding}

Impulse laser welding can join materials with extremely high melting temperature. Heat input takes such a short time that surfaces in the welding zone are heated above the melting temperature before the end of the laser impulse cycle. With the periodicity of the laser impulses and the laser beam scanning, the welded joint is formed. This welding process is the basis of micro laser beam welding. Titanium and titanium alloys can be welded with high penetration depth this way.

Parts to be assembled include a 3D printed base frame (Ti Grade 23, Ti-6Al-4V), filling material (Ti Grade 1, Ø 0,2 mm wire), and the threaded sleeves of the pillars (Ti Grade 5 from turned rolled rod).

Laser welding is implemented in an argon atmosphere and starts with fixing spot welding in order to avoid deformations.

The joining of the workpieces with our cross-sectional design is carried out with filling material (unalloyed, Grade 1) according to the adjusted technical variables of the welding machine (300320 V / 8.5 ms 5.0 Hz, Focus: between 1-2) after circular symmetric deep penetration welding of the root gap (260-280 V 5-8.5 ms $5.0 \mathrm{~Hz}$ focus: between 0 and 2) (Figure 17.).

Facing of the deposited layers: $260-290$ V $8.5 \mathrm{~ms}$ $5.0 \mathrm{~Hz}$, focus between 3-10. Welded joint surface is finished by increasing laser inclination angle and the diameter of the laser spot (Table 2.). The last welding step is the placing of the base plate for the threaded sleeve. After welding, the merged part is subjected again to stress relieving heat treatment.

Final finishing (cleansing of the welded joints, facing of wrinkles) of the welded implant plate structure takes place with complex-geometry polishing tools. Despite digital design and manufacturing, the final finishing stage requires a significant amount of manual work. It consists of the micro-particle ( $50 \mu \mathrm{m}, 1,5 \mathrm{bar})$ blasting of the dorsal surface, which is followed by acid etching to decrease micro grooves on the surface. The process ends with the mirror finishing of the buccal surface (Figure 18.).
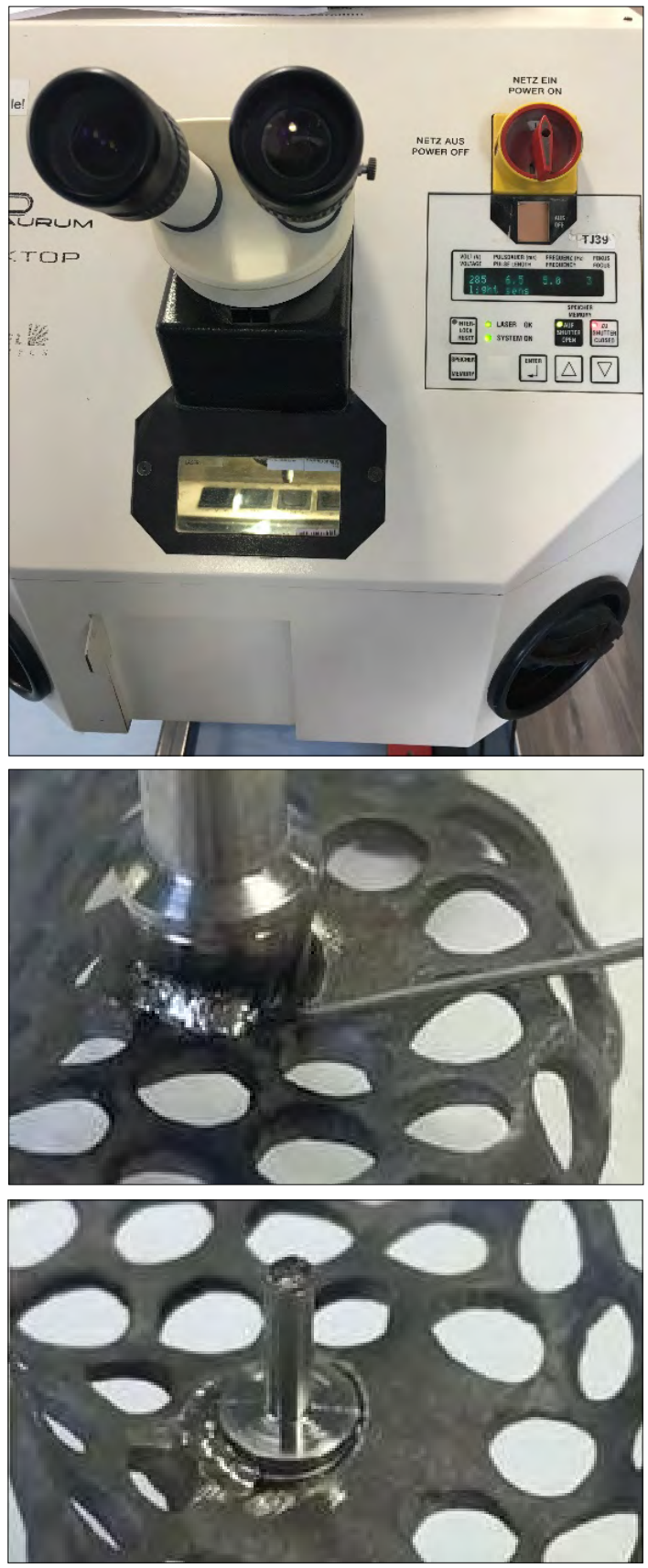

Figure 17. Interface of the laser beam welding unit and the phases of welding

Surface preparation is important at the interface between the implant structure and the mucous membrane and bone tissue, as it influences the osseointegration rate, which increases implant stability. Finally, check assays were conducted on each custom-made implant using micro CT. 
Table 2. Main technical features of our Dentaurum Basel Laser Desktop micro welding unit

\begin{tabular}{|l|l|}
\hline \multicolumn{2}{|c|}{ Parametres of laser welding unit } \\
\hline Laser crystal & Nd: YAG \\
\hline Wavelength & $1064 \mathrm{~nm}$ \\
\hline Max. average power & $50 \mathrm{~W}$ \\
\hline Pulse energy & $50 \mathrm{~J}$ \\
\hline Pulse peak power & $5 \mathrm{~kW}$ \\
\hline Pulse duration & $0.5-20 \mathrm{~ms}$ \\
\hline $\begin{array}{l}\text { Pulse frequency single } \\
\text { pulse }\end{array}$ & $25 \mathrm{~Hz}$ \\
\hline Pulse shape & 4 pre-formed pulse shapes \\
\hline Laser cooling & $\begin{array}{l}\text { integrated water-air-heat } \\
\text { exchanger }\end{array}$ \\
\hline Electrical connection & $200-240 \mathrm{~V} / 50-60 \mathrm{~Hz} / 10 \mathrm{~A}$ \\
\hline $\begin{array}{l}\text { Max. power consump- } \\
\text { tion }\end{array}$ & $2,2 \mathrm{~kW}$ \\
\hline
\end{tabular}
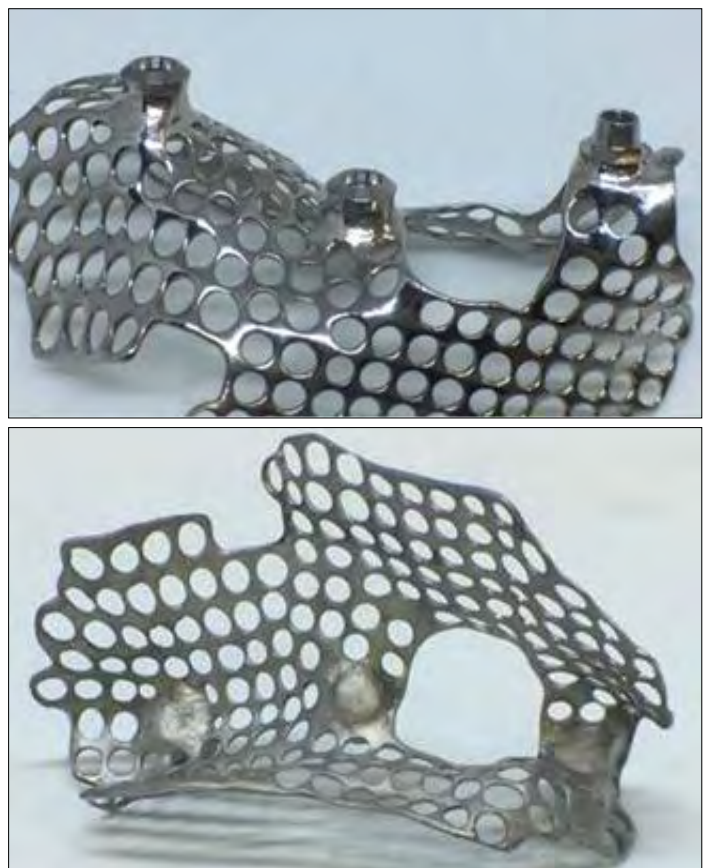

Figure 18. Joined structure of subperiosteal implant after surface processing

\section{Non-destructive material testing with micro CT}

Material homogeneity defects in the welded joint can be analysed during this material testing procedure. These material defects influence mechanical strength, quality, and durability of the welded joint (Figure 19.).
Quality standards were determined based on analyses of tensile test specimens made for welded joint evaluation. Welded joint volume of test specimens had to have a homogeneity of $90 \%$ evaluated by micro CT, and the size of the largest void could not exceed $0.05 \mathrm{~mm}^{3}$. Moreover, its distance from the material surface had to be greater than $0.3 \mathrm{~mm}$.

\section{Metallographic analysis of the weld- ed joint of the test specimen}

For welding joint quality analysis a trial implant, with a material and manufacturing technology identical to the original implant, was manufactured. A metallographic section was microscopically analysed after acid etching (with a Nikon TS100 microscope) (Figure 20.).

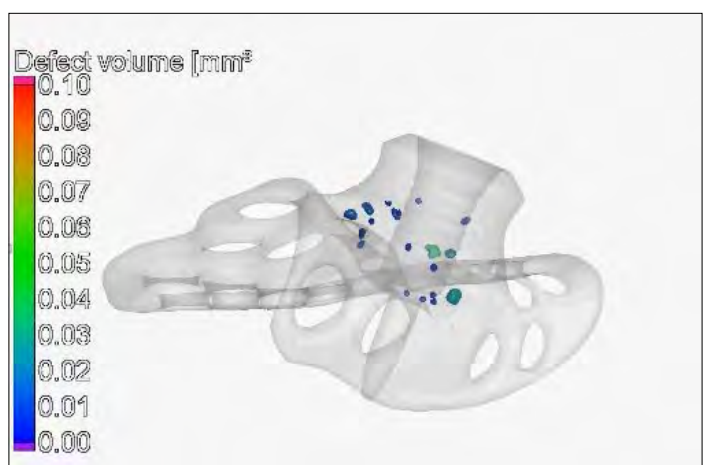

Figure 19. Micro CT evaluation of the test specimen's welded joint

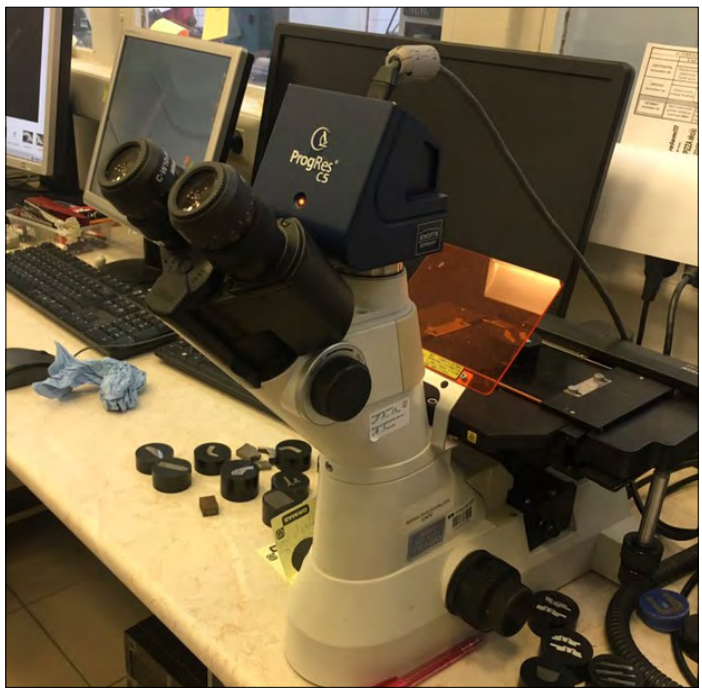

Figure 20. Microscope used for metallographic analysis 
No significant grain coarsening takes place during laser micro welding. The heat affected zone is also narrow. These kinds of welding joints are advantageous from several points of view: homogeneous joint structure with uniform and consistent heat affected zone (Figure 21.).

Cut position and metallographic section were chosen to show the largest welding void fractions according to micro CT images. See marked positions in Figure 22.

\section{Summary}

Implantation of the final screw-fixed denture takes place after the completed mucous membrane recovery over the dental implant, and after proper osseointegration titanium frame surrounding bone tissue (Figure 23. and 24.).

Our completely re-thought and manufacturing technologically developed subperiosteal implant
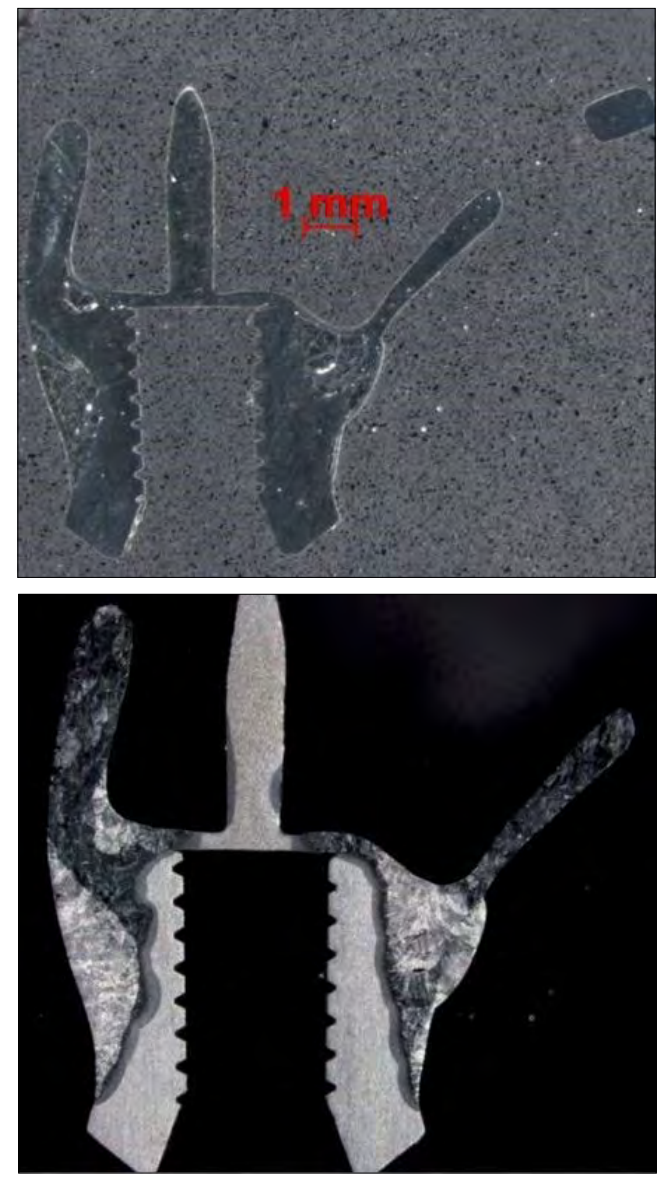

Figure 21. Structural and sectional photos the welded titanium structure with dual-phase fixing points represents a novel technical solution regarding both its material and the complex technology of its geometric design. Separable, dual-phase fixing locations allow isolated healing under skin level. Subgingival mucous surface irritation during surgical wound closure and after healing is reduced by the minimising of welded sleeve height. It helps patients for whom conventional cylindrical dental implants are not an option due to the patient's insufficient bone volume resulting from tooth loss and bone resorption.

\section{Acknowledgement}

We would like to thank for the support provided within "Internationalization, initiatives to establish a new source of researchers and graduates and development of knowledge and technological transfer as instrument of intelligent specializations at Széchenyi István University” project.
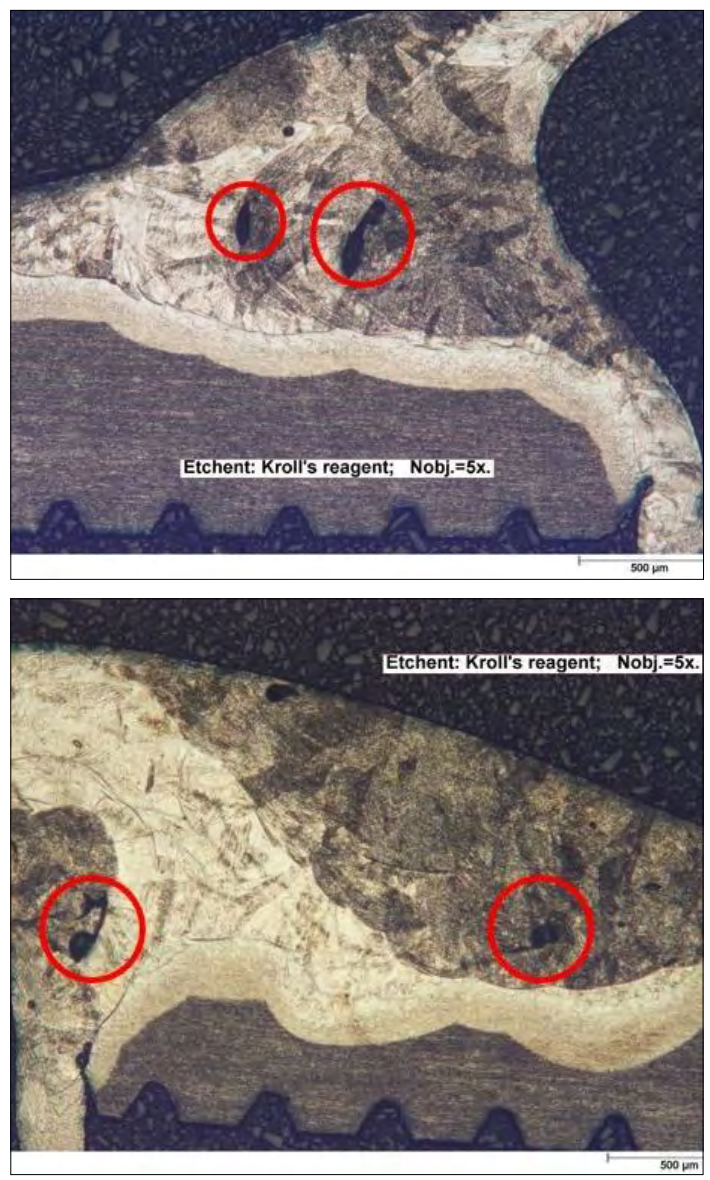

Figure 22. Sectional images of the welded titanium frame structure with marked void fractions 

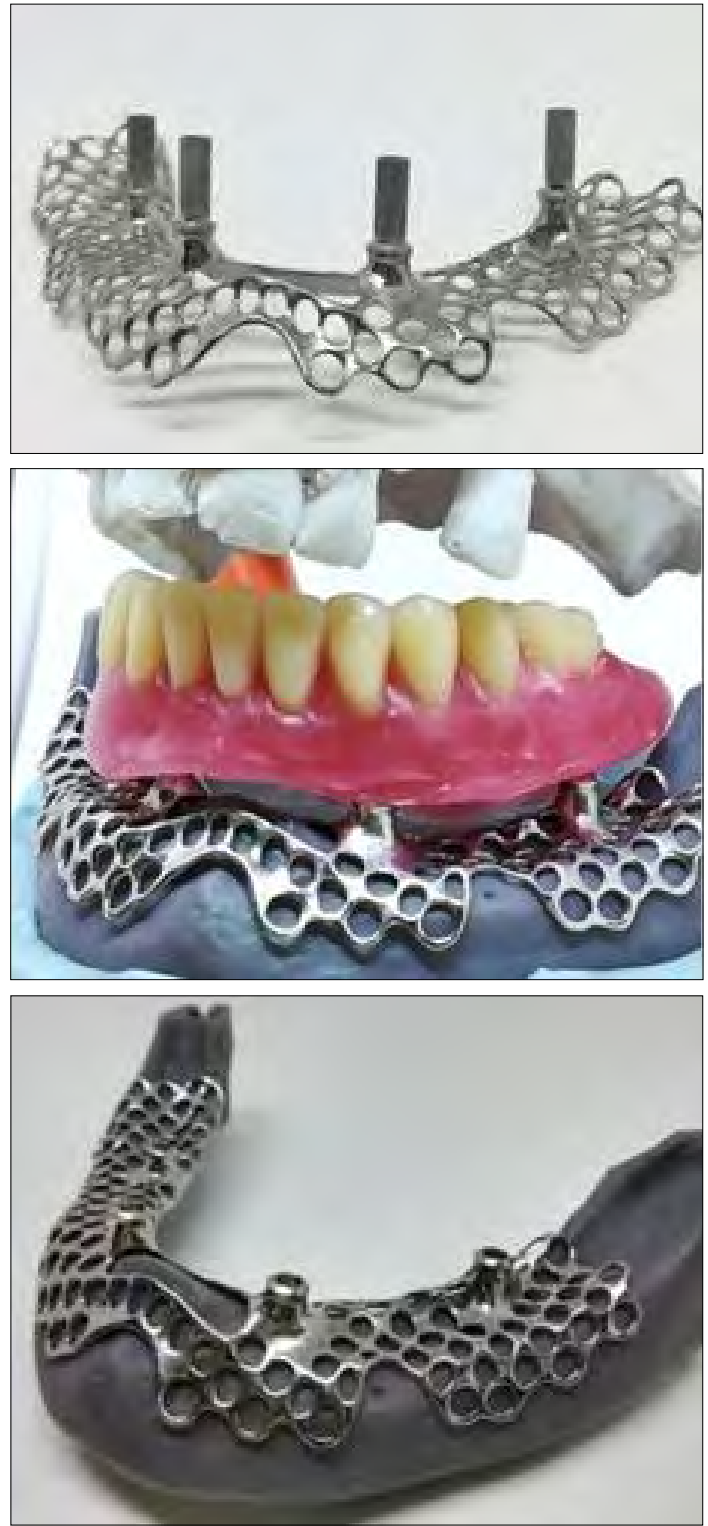

Figure 23. Finished implant frames together with denture model before sterilising

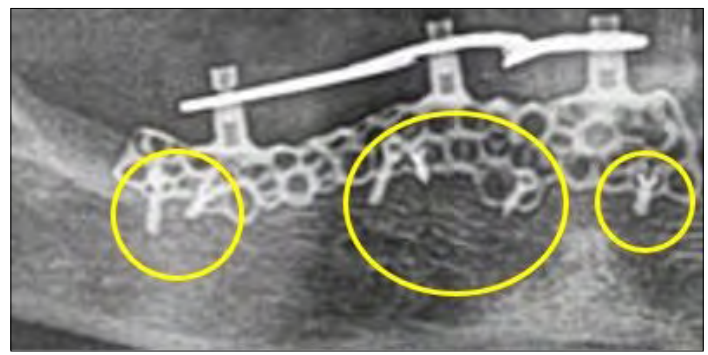

Figure 24. X-ray image of implanted custom-made subperiosteal implant with fixing screws

\section{References}

[1] Malinov S., Sha W.: Application of artifical neural networks for modeling correlations in titanium alloy. Materials Science and Engineering A, 41/1-2. (2010) 140-146. https://doi.org/10.1016/j.msea.2003.09.029

[2] Shrivastava S.: Medical Device Materials, Anaheim $C A$. In: Proceedings of the Materials and Processes for Medical Devices Conference, 2003. 417. https://www.asminternational.org/documents/10192/1849770/06974g_frontmatter.pdf

[3] Xie J., Safarevich S.: Laser materials porcessing for medical devices. In: Shrivastava S. (ed.): Proceedings of the Materials and Processes for Medical Devices Conference, Anaheim, CA, ASM International. 2003. 25-30.

[4] Saresh N., Gopalakrishna Pillai M., Mathew J.: Investigations into the effects of electron beam welding on thick Ti-6Al-4V titanium alloy. Journal of Materials Technology, 192-193. (2007) 83-88. https://doi.org/10.1016/j.jmatprotec.2007.04.048

[5] Welding Handbook. Weldings Processes. vol. 2., American Welding Society, Miami, FL, 1988. 695697.

[6] Welding Handbook. Metals and Their Weldability, vol. 4., American Welding Society, Miami, FL, 1982. 447-449.

[7] Gupta B., Krishna V. G.: Aerospace Materials, vol. 1., S-Chand and Company Ltd., New Delhi, India, 1996.

[8] Kelly S. M, Kapmpe S. L.: Microstructural evolution in laser-deposited multilayer Ti-6Al-4V builds.PartII.Thermalmodeling. Metallurgicaland Materials Transactions, A 35/6. (2004) 1869-1879. https://doi.org/10.1007/s11661-004-0095-7

[9] Qian L., Mei K., Liang J., Wu X.: Influence of position and laser power on thermal history and microstructure of direct laser fabricated Ti-6Al-4V samples. Materials Science and Technology, 21/5. (2005) 597-605. https://doi.org/10.1179/174328405X21003

[10] Dinda G. p., Song L., Mazumder J.: Fabrication of Ti-6Al-4V scaffolds by direct metal deposition. Metallurgical and Material Transactions A - Physical Metallurgy and Materials Science, 39/12. (2008) 2914-2922. https://doi:10.1007/s11661-008-9634-y

[11] Nowotny S., Scharek S., Beyer E., Richter K. H.: Laser beam build-up welding: precision in repair, surface cladding, and direct $3 D$ metal deposition. Journal of Thermal Spray Technology, 16/3. (2007) 344-348. https://doi:10.1007/s11666-007-9028-5

[12] Taminger K. M., Hafley R. A.: Electron beam freeform fabrication for cost effective nearnet shape manufacturing. In: NATO/RTO AVT-139 specialists meeting on cost effective manufacture via net shape processing, 
Amsterdam (The Netherlands): NATO, (2006) https://ntrs.nasa.gov/archive/nasa/casi.ntrs.nasa. gov/20080013538.pdf

[13] Katou M., Oh J., Miyamoto Y., Matsuura K., Koduh M.: Freeform fabrication of titanium metal and intermetallic alloys by three-dimensional micro welding. Materials and Design, 28/7. (2008) 2093-2098. https://doi.org/10.1016/j.matdes.2006.05.024

[14] Clark D., Bache M., Whittaker M.: Shaped metal deposition of a nickel alloy for aero engine applications. Journal of Materials Processing Technology, 203/1-3. (2008) 439-448. https://doi.org/10.1016/j.jmatprotec.2007.10.051

[15] Baufeld B., Van der Biest O., Gault R.: Additive manufacturing of Ti-6Al-4V components by shaped metal deposition: $\mathrm{Mi}$ crostructure and mechanical properties. Materials and Design, 31/1. (2010) 106-111. https://doi.org/10.1016/j.matdes.2009.11.032

[16] Barreda J. L., Santamaram F., Azpiroz X., Irisarri A. M., Varona J. M.: Electron beam welded high thickness Ti-6Al-4V plates using filler metal of similar and different composition to the base plate. Vacuum 62/2-3. (2001) 143-150. https://doi.org/10.1016/S0042-207X(00)00454-1
[17] Baeslack W. A., Becker D. W., Froes F. H.: Advances in titanium alloy welding metallurgy. Journal of Metals, 36/5. (1984) 46-82. https://slideheaven.com/queue/advances-in-titanium-alloy-welding-metallurgy.html

[18] Balasubramanian M., Jayabalan V., Balasubramanian V.: Developing mathematical models to predict tensile properties of pulsed current gas tungsten arc welded Ti-6Al-4V alloy. Materials and Design, 29/1. (2008) 92-97. https://doi.org/10.1016/j.matdes.2006.12.001

[19] Li X., Xie J., Zhou Y.: Effects of oxygen contamination in the argon shielding gas in laser welding of commercially pure titanium thin sheet. Journal of Materials Science, 40/13. (2005) 3437-3443. http://www.camj.uwaterloo.ca/pdf/Zhou/JMS2005\%20Li.pdf

[20] Brandl E., Baufeld B., Leyens C., Gault R.: Additive manufactured Ti-6Al-4V using welding wire: comparison of laser and arc beam deposition and evaluation with respect to aerospace material specifications. ScienceDirect - Physics Prodedia, 5/1. (2010) 595-606. https://doi.org/10.1016/j.phpro.2010.08.087 